Check for updates

Cite this: RSC Adv., 2019, 9, 18989

\title{
Surface amino-functionalization of Sn-Beta zeolite catalyst for lactic acid production from glucose $\uparrow$
}

\author{
Zheng Shen, (DD ab Ling Kong, ${ }^{a}$ Wei Zhang, ${ }^{\mathrm{b}}$ Minyan Gu, ${ }^{a}$ Meng Xia, ${ }^{\mathrm{b}}$ Xuefei Zhou ${ }^{\mathrm{b}}$ \\ and Yalei Zhang $\mathbb{D}$ *ab
}

The catalytic conversion of glucose into lactic acid (LA) provides an alternative approach for LA production to bio-fermentation. Nevertheless, during the process, the dehydration of glucose and fructose into 5hydroxymethylfurfural catalyzed by Brønsted acid exists as the main side reaction that leads to the decrease in LA yield. In order to promote the yield and selectivity of LA, a series of acid-base bifunctional $\mathrm{Sn}$-Beta- $\mathrm{NH}_{2}$ catalysts were prepared by post-grafting aminopropyl groups with the surface silanol groups of $\mathrm{Sn}$-Beta zeolite. The catalysts were systematically characterized by X-ray diffraction, $\mathrm{N}_{2}$ adsorption-desorption, elemental analysis, $\mathrm{X}$-ray photoelectron spectroscopy, Fourier transform infrared spectra analysis following pyridine adsorption, and $\mathrm{CO}_{2}$ temperature-programmed desorption. The asprepared $\mathrm{Sn}$-Beta- $\mathrm{NH}_{2}$ catalysts exhibiting both Lewis acid and moderate base sites facilitated the conversion of glucose to LA in competition with undesirable side reactions. In addition, effects of reaction parameters including reaction temperature and time, catalyst dosage, and glucose concentration were investigated. A high LA yield up to $56 \%$ was achieved under optimized hydrothermal conditions $\left(190^{\circ} \mathrm{C}, 2 \mathrm{~h}\right)$, along with a complete conversion of glucose and a 5-hydroxymethylfurfural yield of $7 \%$. The result indicated an alternative modification method of Sn-Beta zeolite for a more favorable LA yield.

Received 19th February 2019

Accepted 5th May 2019

DOI: $10.1039 / c 9 r a 01264 h$

rsc.li/rsc-advances its subsequent separation process are all complex and of low efficiency. Additionally, the inevitable use of lime as the neutralization agent may lead to the production of calcium sulfate waste. Compared to bio-fermentation, chemical catalytic reactions provide a more acceptable approach for LA production from biomass instead of grain because of its potential for large-scale production and higher efficiency. ${ }^{\mathbf{1 4 , 1 5}}$

Up to date, great efforts have been devoted to synthesizing multiple catalysts for the conversion of carbohydrates into LA, including homogenous and heterogeneous catalysts. Homogenous catalysts, such as metal salts $\left(\mathrm{Pb}^{2+}\right),{ }^{16}$ alkaline-earth metal hydroxides $\left(\mathrm{Ca}(\mathrm{OH})_{2}\right.$ and lanthanide catalysts $\left(\mathrm{ErCl}_{3}\right.$ and $\left.\left.\mathrm{Er}(\mathrm{OTf})_{3}\right)\right),{ }^{17-19}$ always exhibit outstanding catalytic performance in the process of biomass conversion to produce LA. However, the separation and recovery of these catalysts may hinder their practical application. Another widely studied route is the synthesis of heterogeneous catalysts, such as metal oxides $\left(\mathrm{Nb}_{2} \mathrm{O}_{5}, \mathrm{CuO}\right.$ and $\mathrm{Al}-\mathrm{Zr}$ mixed oxides $),{ }^{20-22}$ solid acid catalysts (AlW and $\mathrm{Er} / \mathrm{K} 10)^{\mathbf{2 3 , 2 4}}$ and zeolite catalysts (Sn-Beta). ${ }^{\mathbf{1 4 , 2 5}}$

Among numerous heterogeneous catalysts, Sn-Beta zeolite has shown benign catalytic performance because of its stability and various Lewis acid sites generated from Sn. ${ }^{25-27}$ Therefore, much attention has been paid to the modification of Sn-based zeolites. In order to accelerate the diffusion of glucose and fructose molecules, Zhang et al. synthesized a hierarchical SnBeta zeolite catalyst and a $72 \%$ alkyl lactate yield was
${ }^{a}$ National Engineering Research Center of Protected Agriculture, Tongji University, Shanghai, 200092, China.E-mail: zhangyalei@tongji.edu.cn

${ }^{b}$ State Key Laboratory of Pollution Control and Resource Reuse, Tongji University, Shanghai, 200092, China

$\dagger$ Electronic supplementary information (ESI) available. See DOI: $10.1039 / \mathrm{c} 9 \mathrm{ra} 01264 \mathrm{~h}$ 
obtained from sucrose. ${ }^{28}$ Wan et al. found that Sn-Beta supported gold catalyst could readily convert acetol to LA with a yield up to $73 \%$ under hydrothermal conditions. ${ }^{29}$

During the reaction process of glucose conversion, there exist some side reactions that may lead to the decrease of LA yield, including the dehydration of glucose and fructose to 5hydroxymethylfurfural (HMF) and the rehydration of HMF to formic acid and levulinic acid. Moreover, the generated LA may inevitably act as a Brønsted acid to catalyze these side reactions. In order to suppress the side reactions, researchers attempted to add base into the reaction solution, followed by the recovery of lactic acid with the aid of acid neutralization. ${ }^{30}$ But this approach brings additional cost and may lead to corrosion to the reactor. To avoid the use of liquid base, Dong et al. firstly developed a $\mathrm{Sn}-\mathrm{Zn}$-Beta catalyst that contained both Lewis acid and base sites and a $48 \%$ LA yield was obtained. ${ }^{14}$ It was a novel thought to modify the Sn-Beta zeolite with another metal to form heterogeneous catalysts with both acidic and basic catalytic sites. Apart from the introduction of metal atoms, the plenty silanol groups on the surface of Beta zeolite are also favorable for modification by organic functional groups. Postgrafting method is a common method for organic functionalization. By the reaction of silanol groups and functionalization reagents to form corresponding covalent bond, the surface hydrophilicity/hydrophobicity or acidity/basicity of Beta zeolite could be adjusted. In addition, compared to metal modification, surface modification with covalently bound organic functional groups could also promote the interaction and collision opportunity with organic substrates, leading to a further increase in reaction efficiency.

Here, we developed a new method to modify Sn-Beta zeolite with amino groups, in order to strengthen its basicity while not decrease its acidity drastically. By post-grafting organoamines with the surface silanol groups of the zeolite materials, highly stable catalysts containing solid acid and base catalytic sites could be synthesized. The surface amino-functionalization of supporters has already been conducted to the surface modification of silica, ${ }^{31}$ MCM-48, ${ }^{32,33}$ SBA-15, ${ }^{34,35}$ MCM-41 ${ }^{36}$ and ion exchange resins. ${ }^{37}$ The structural and physicochemical properties of the catalysts were systematically characterized upon functionalization and the functionalized catalysts exhibited improved activity for the self-condensation of cyclohexanone, Knoevenagel reaction, and Henry reaction. ${ }^{32-37}$ Considering that the Sn-Beta zeolite contains surface silanol groups, it could also be modified by surface amino-functionalization. Herein, we report that glucose can be efficiently converted to LA under hydrothermal conditions over amino groups functionalized SnBeta catalyst. A systematical optimization of reaction parameters is conducted and the possible reaction pathway is also proposed based on structural and acid-base characterization.

\section{Experimental}

\section{Materials}

All reagents were used without further purification. Beta zeolite was obtained from the Catalyst Plant of Nankai University. Tin(II) acetate (95\%), lactic acid (LA) (1.0 N), 5- hydroxymethylfurfural (HMF) (97\%), levulinic acid (LeA) (98\%) were obtained from Alfa Aesar. 3-Aminopropyltrimethoxysilane (APTMS) (98\%) was obtained from Wako. Formic acid (FA) (99\%) was obtained from J\&K China Chemical Co., Ltd. Phosphoric acid (HPLC) was obtained from Sigma-Aldrich. Nitric acid (GR), ethanol (AR), D-(+)-glucose (AR) were obtained from Sinopharm Chemical Reagent Co., Ltd.

\section{Catalysts synthesis}

Commercial Beta zeolite was dealuminated by stirring in $\mathrm{HNO}_{3}$ solution $(13 \mathrm{M})$ at $80{ }^{\circ} \mathrm{C}$ for $20 \mathrm{~h}$ with a $\mathrm{HNO}_{3}(\mathrm{~mL}) /$ Beta zeolite (g) ratio of 20. After filtrating, washing with a large amount of deionized water until the supernatant was neutral, drying at $150{ }^{\circ} \mathrm{C}$ overnight, the dealuminated Beta zeolite was obtained and denoted as deAl-Beta. Solid-state ion exchange (SSIE) was then performed by grinding $0.2 \mathrm{~g}$ of $\operatorname{tin}(\mathrm{II})$ acetate with $1.0 \mathrm{~g}$ of dealuminated zeolite for $30 \mathrm{~min}$. Finally, the sample was calcined in an air flow at $550{ }^{\circ} \mathrm{C}$ for $6 \mathrm{~h}$ with a ramp of $5{ }^{\circ} \mathrm{C} \min ^{-1}$ and was denoted as Sn-Beta. ${ }^{38}$

As to the synthesis of surface amino-functionalizated SnBeta zeolite (Sn-Beta- $\mathrm{NH}_{2(v)}, v$ represents the volume of APTMS used $(\mu \mathrm{L}))$, in a typical run, $0.5 \mathrm{~g}$ of Sn-Beta zeolite and a certain volume of APTMS were dissolved into $250 \mathrm{~mL}$ of ethanol in a $500 \mathrm{~mL}$ round-bottomed flask equipped with a reflux condenser. After stirring at $80{ }^{\circ} \mathrm{C}$ for $6 \mathrm{~h}$, the white precipitates were collected by centrifugation and followed by washing with a large amount of ethanol. Then, the sample was dried at $80{ }^{\circ} \mathrm{C}$ overnight to obtain $\mathrm{Sn}-\mathrm{Beta}-\mathrm{NH}_{2}$ catalyst.

\section{Catalysts characterizations}

The X-ray diffraction (XRD) patterns of the catalysts were recorded on a Bruker D8 Advance X-ray powder diffractometer with $\mathrm{Cu} \mathrm{K} \alpha$ radiation of $\lambda=1.54 \AA$ ( $40 \mathrm{kV}$ and $40 \mathrm{~mA})$ from $2 \theta 5=$ $10^{\circ}$ to $90^{\circ}$ with a scan speed of $2^{\circ} \mathrm{min}^{-1} \cdot \mathrm{N}_{2}$ adsorptiondesorption isotherms measurements were performed using a Micromeritics ASAP 2460 analyzer at $-196{ }^{\circ} \mathrm{C}$. Prior to the analysis, samples were degassed at $150{ }^{\circ} \mathrm{C}$ for $6 \mathrm{~h}$ under vacuum. The total surface area was calculated by employing the multipoint BET method and the microporous pore volume was determined using the $t$-plot method. The $\mathrm{C}$ and $\mathrm{N}$ contents of the $\mathrm{Sn}-\mathrm{Beta}-\mathrm{NH}_{2}$ catalysts were determined on Elementar Vario EL III elemental analyzer at $1000^{\circ} \mathrm{C}$. The contents of $\mathrm{Si}$ and $\mathrm{Al}$ of the catalysts were measured by inductively coupled plasma optical emission spectroscopy (ICP-OES, PerkinElmer Optima 2100DV). Prior to the measurements, the samples were digested in an acidic mixture ( $\left.\mathrm{HCl}-\mathrm{HNO}_{3}-\mathrm{HF}\right)$ at $150{ }^{\circ} \mathrm{C}$ for $12 \mathrm{~h}$. X-ray photoelectron spectroscopy (XPS) studies were performed on a RBD upgraded PHI-5000C ESCA system (PerkinElmer) with Al $\mathrm{K} \alpha$ radiation $(h \nu=1486.6 \mathrm{eV})$. Charge referencing was done against adventitious carbon $\left(\mathrm{C}_{1 \mathrm{~s}}\right.$ at $\left.284.6 \mathrm{eV}\right)$. The acidic properties of the catalysts were tested by adsorption, followed by temperature programmed desorption (TPD) of pyridine using Fourier transform infrared spectroscopy (Py-IR). The Py-IR spectra were recorded on a PerkinElmer Frontier FT-IR in the range of 1400-1700 $\mathrm{cm}^{-1}$ with a resolution of $2 \mathrm{~cm}^{-1}$. A $10 \mathrm{mg}$ of sample was pressed into a self-supported wafer with a diameter 
of $13 \mathrm{~mm}$. Then, the wafer was set in a quartz IR cell which was sealed with $\mathrm{CaF}_{2}$ windows and connected to a vacuum system. The samples were evacuated at $450{ }^{\circ} \mathrm{C}$ for $2 \mathrm{~h}$ under vacuum. After cooling, pyridine vapor was employed into the cell and the adsorption was performed for $0.5 \mathrm{~h}$. Subsequently, desorption steps were conducted at different temperatures $\left(25^{\circ} \mathrm{C}, 150{ }^{\circ} \mathrm{C}\right.$ and $250{ }^{\circ} \mathrm{C}$ ) for $1 \mathrm{~h}$. The alkaline properties of the samples were performed on Micromeritics AutochemII 2920 chemisorption analyzer using the $\mathrm{CO}_{2}$-TPD method. The sample was first purged with $\mathrm{Ar}$ and then heated to $550{ }^{\circ} \mathrm{C}$ at a rate of $10^{\circ} \mathrm{C} \mathrm{min}{ }^{-1}$ for $1 \mathrm{~h}$ and finally cooled to $45^{\circ} \mathrm{C}$. The surface of the catalyst was saturated with $\mathrm{CO}_{2}$ for $30 \mathrm{~min}$ at this temperature, and then, the excess $\mathrm{CO}_{2}$ was purged with Ar blowing. The TPD curve of the sample was obtained at the temperature range from 45 to $800{ }^{\circ} \mathrm{C}$ with a heating rate of $10{ }^{\circ} \mathrm{C} \min ^{-1}$ under an $\mathrm{Ar}$ flow and a flowing rate of $30 \mathrm{~cm}^{3} \mathrm{~min}^{-1}$.

\section{Catalytic reactions and products analysis}

The catalytic conversion of glucose to LA was carried out in a Teflon-lined stainless steel autoclave reactor with an inner volume of $50 \mathrm{~mL}$. In a typical procedure, $225 \mathrm{mg}$ of glucose (7.5 mmol of carbon) and $160 \mathrm{mg}$ of catalyst were mixed in $10 \mathrm{~mL}$ of $\mathrm{H}_{2} \mathrm{O}$ in the autoclave, followed by heating to the desired reaction temperature $\left(190{ }^{\circ} \mathrm{C}\right)$ and keeping for the appropriate time $(2 \mathrm{~h})$. After reaction, the autoclave was cooled, and the liquid mixture was separated by centrifugation and filtration. The concentrations of organic acids, HMF and sugars were analyzed on an Agilent 1200 series HPLC. For organic acids and HMF, a Gemini-NX 5u C18 column was used with a UV detector $(210 \mathrm{~nm})$ using a $0.1 \%$ aqueous phosphoric acid as the mobile phase with a flow rate of $1 \mathrm{~mL} \mathrm{~min}^{-1}$. The column temperature was $30{ }^{\circ} \mathrm{C}$. The glucose concentration was analyzed using a RI detector (Bio-Rad HPX-87H column) and the column and RI detector temperature were $55^{\circ} \mathrm{C}$ and $45{ }^{\circ} \mathrm{C}$, respectively. The mobile phase was a $5 \mathrm{mM}$ aqueous sulphuric acid solution with a flow rate of $0.5 \mathrm{~mL} \mathrm{~min}^{-1}$. All the concentrations were determined based on the external standard. The conversion of sugars was defined as the moles of sugars reacted divided by initial sugars moles used in the system and the product yields were determined based on carbon. All experiments were performed for more than three times and the quantitative data were the average values of the analytical results. The relative errors were less than $10 \%$ for all experiments.

\section{Results and discussion}

\section{Catalysts preparation and characterizations}

The Sn-Beta- $\mathrm{NH}_{2}$ catalyst was synthesized from a combined strategy of both Sn loading and organoamines functionalization..$^{32,33,36,37}$ As proposed in Fig. 1, commercial Beta zeolite was pretreated using $\mathrm{HNO}_{3}$ to remove most of $\mathrm{Al}$ species in the framework. Then, the $\mathrm{Sn}$ sites were incorporated into the dealuminated zeolite by SSIE. The synthesis of the bifunctional catalyst, or the post-grafting of organoamine groups, was carried out by stirring a certain amount of APTMS with Sn-Beta zeolite in a polar solvent ethanol. Thus, organoamines were

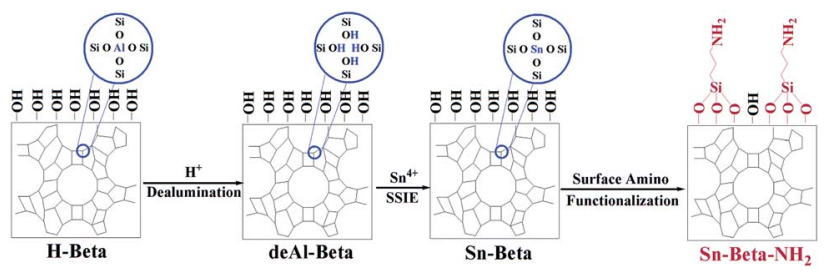

Fig. 1 Proposed procedures for preparation of the $\mathrm{Sn}$-Beta- $\mathrm{NH}_{2}$ catalyst.

grafted on the Sn-Beta zeolites surface in formation of $\mathrm{Si}-\mathrm{O}-\mathrm{Si}$ bonds.

The XRD patterns in Fig. 2A confirmed that the topology of Beta zeolite was well preserved for the prepared deAl-Beta in $\mathrm{HNO}_{3}$ solution. Then the structure of deAl-Beta changed during the process of incorporation of Sn species. The intensity of the peak located at $2 \theta=22.5-22.6^{\circ}$ decreased after $\mathrm{Sn}$ incorporation, indicating a lower crystallinity. The $\mathrm{Sn}-\mathrm{Beta}-\mathrm{NH}_{2}$ possessed a similar crystallinity to Sn-Beta, showing that the further postgrafting of organoamines process did not destroy the Sn-Beta zeolite structure. Meanwhile, a slight amount of tin oxide was observed, as evidenced by the occurrence of the peaks at $26^{\circ}$, $34^{\circ}$ and $51^{\circ}$, possibly due to the high dosage of tin(II) acetate used during the SSIE procedure. ${ }^{39}$ Fig. $2 \mathrm{~B}$ presents the $\mathrm{N}_{2}$ adsorption-desorption isotherms of all catalysts. Typical type-I and type-IV isotherms with two steep steps at the relative pressure of $P / P_{0}<0.01$ and $0.6<P / P_{0}<0.9$, corresponding respectively to micropore filling and capillary condensation in the mesopores, were observed. It can also be confirmed that the most probable pore sizes of all catalysts were about $3.9 \mathrm{~nm}$ (Fig. S1 $\dagger$ ), indicating that the post-grafting of organic functional groups did not influence the mesopore size of Sn-Beta zeolite.

Table 1 summarizes the physicochemical properties of the Beta-type zeolites. The $\mathrm{N}$ contents of Sn-Beta- $\mathrm{NH}_{2(30)}$ and $\mathrm{Sn}$ Beta- $\mathrm{NH}_{2(200)}$ catalysts measured by $\mathrm{CHN}$ elemental analysis were approximately $0.2 \mathrm{wt} \%$ and $0.8 \mathrm{wt} \%$, respectively. The former value was similar to the theoretical value on the grounds of the dosage of APTMS, while the latter one was lower than the theoretical value. The results of ICP-OES show that the elemental ratio of $\mathrm{Si} / \mathrm{Al}$ increased from 25 for commercial Beta zeolite to over 1700 for Sn-Beta and Sn-Beta- $\mathrm{NH}_{2}$, indicating that $\mathrm{Al}$ was almost completely removed during the nitric treatment process. Fig. 3A gives the XPS spectra of Sn-Beta- $\mathrm{NH}_{2(30)}$ catalyst with five main elements including $\mathrm{Si}, \mathrm{C}, \mathrm{N}, \mathrm{Sn}$ and $\mathrm{O}$. The peaks
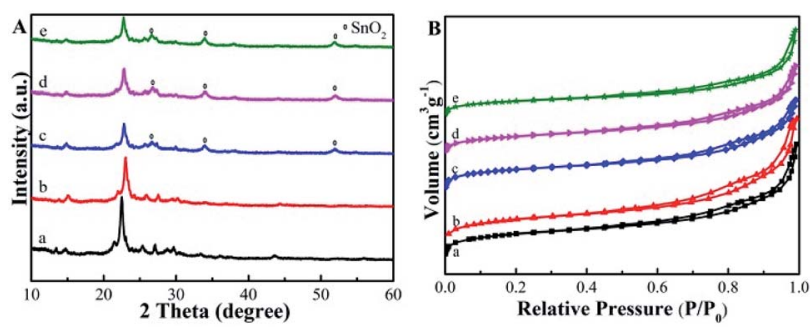

Fig. 2 (A) Powder XRD patterns of the samples. (B) $\mathrm{N}_{2}$ sorption isotherms of the samples. The samples are: (a) Beta, (b) deAl-Beta, (c) $\mathrm{Sn}-\mathrm{Beta}$, (d) Sn-Beta- $\mathrm{NH}_{2(30)}$ and (e) Sn-Beta- $\mathrm{NH}_{2(200)}$. 
Table 1 Physicochemical properties of the Beta-type zeolites

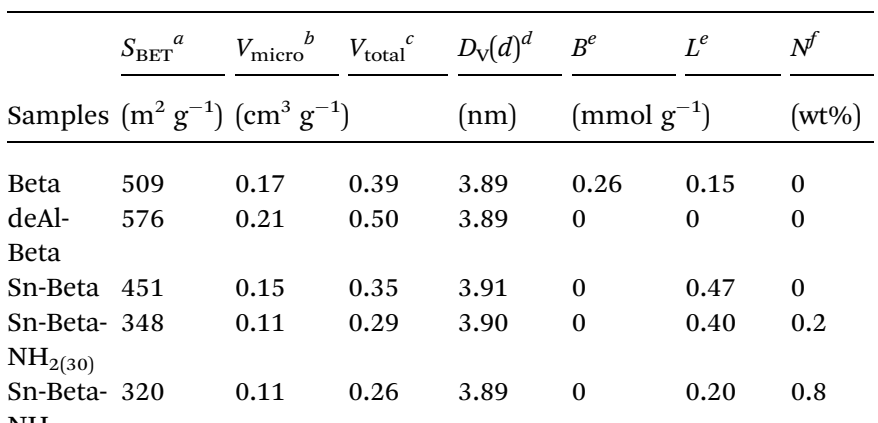

$\mathrm{NH}_{2(200)}$

${ }^{a}$ BET surface area. ${ }^{b}$ Micropore volume, calculated by the $t$-plot method. ${ }^{c}$ Single point total pore volume at $P / P_{0}=0.95 .{ }^{d}$ The most probable aperture. ${ }^{e}$ The number of Brønsted acid and Lewis acid sites based on pyridine IR adsorption at $423 \mathrm{~K} .{ }^{f}$ Determined by CHN elemental analysis.

that were observed in the Fig. 3B at 487.1 and $495.5 \mathrm{eV}$ could be assigned to $S n 3 d_{3 / 2}$ and $S n 3 d_{5 / 2}$, respectively. These two peaks were obviously different from the peaks of extra-framework octahedral Sn species, as often observed at 494.5 and $486.1 \mathrm{eV} \cdot{ }^{40}$ Combined with the XRD results, it can be confirmed that Sn-Beta zeolite synthesized by SSIE method contained some tetrahedrally coordinated Sn species different from $\mathrm{SnO}_{2}$. The $\mathrm{C}_{1 \mathrm{~s}}$ spectra of Sn-Beta- $\mathrm{NH}_{2(30)}$ catalyst was shown in Fig. 3C. The most intensive peak observed at $284.6 \mathrm{eV}$ was attributed to $\mathrm{C}-\mathrm{H}$ in APTMS. The presence of amine groups $\left(-\mathrm{NH}_{2}\right)$ was evident from the $\mathrm{N}_{1 \mathrm{~s}}$ spectra shown in Fig. 3D. The standard binding energy for the free amine group fell in the region of 399-401 eV. Thus, the peak at $399.9 \mathrm{eV}$ was assigned to the $-\mathrm{NH}_{2}$, while the peak at $401.9 \mathrm{eV}$ may be attributed to protonated amine group. ${ }^{41}$

The pyridine-probed FTIR analysis can distinguish the Brønsted and Lewis acid sites readily. Shown in Fig. 4A are the IR spectra of pyridine adsorbed on various catalysts at $150{ }^{\circ} \mathrm{C}$. For deAl-Beta zeolite, all bands corresponding to the Brønsted acid (bands at 1544 and $1633 \mathrm{~cm}^{-1}$ ) and Lewis acid sites (bands
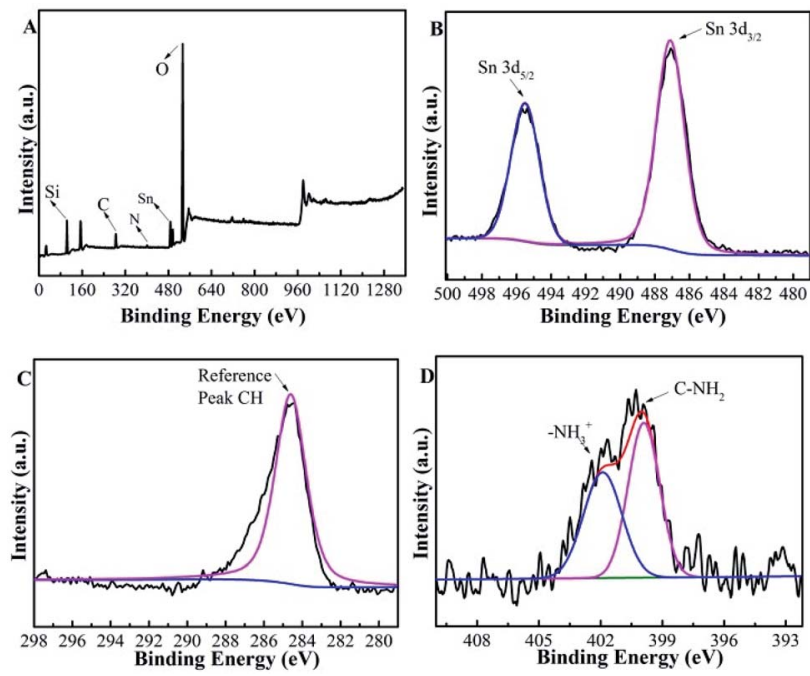

Fig. 3 XPS spectra of (A) Sn-Beta- $\mathrm{NH}_{2(30)}$, (B) $\mathrm{Sn}_{3} \mathrm{~d}$, (C) $\mathrm{C}_{1 \mathrm{~s}}$ and (D) $\mathrm{N}_{1 \mathrm{~s}}$.
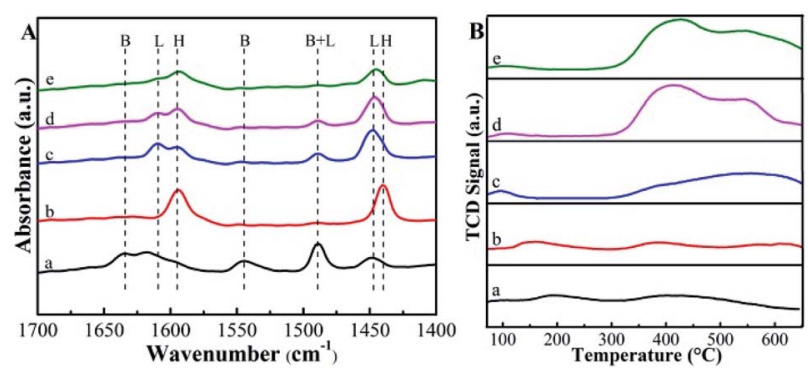

Fig. 4 (A) Py-IR spectra of the samples at $150^{\circ} \mathrm{C}$. (B) $\mathrm{CO}_{2}-\mathrm{TPD}$ profiles of the samples. The samples are (a) Beta, (b) deAl-Beta, (c) Sn-Beta, (d) $\mathrm{Sn}-$ Beta- $\mathrm{NH}_{2(30)}$ and (e) Sn-Beta- $\mathrm{NH}_{2(200)}$.

at 1448 and $1610 \mathrm{~cm}^{-1}$ ) disappeared after dealumination by $\mathrm{HNO}_{3}$. The subsequent incorporation of $\mathrm{Sn}$ species enhanced the Lewis acid sites, confirmed by the strong absorption band at $1448 \mathrm{~cm}^{-1}$. After post-grafting organoamine groups, the Lewis acidity was weakened due to the alkalinity of the amine groups and the screening of $\mathrm{Sn}$ by the amine groups. When the dosage of APTMS was $30 \mu \mathrm{L}$, the Lewis acid sites $\left(0.40 \mathrm{mmol} \mathrm{g}^{-1}\right)$ decreased slightly compared to Sn-Beta zeolite $\left(0.47 \mathrm{mmol} \mathrm{g}^{-1}\right)$. Meanwhile, when the dosage was further increased to $200 \mu \mathrm{L}$, the quantity of Lewis acid sites decreased to $0.20 \mathrm{mmol} \mathrm{g}^{-1}$ (Table 1). The decrease in active sites was ascribed to the bulky aminopropyl groups, which were spatially spaced on the surface of catalysts. ${ }^{34}$ Actually, as the distances between the post-grafted aminopropyl groups were small on average, ${ }^{36}$ it may lead to a negative effect on the functionality of Sn species both in the characterization and reaction, especially under the APTMS dosage of $200 \mu \mathrm{L}$. But the Lewis acid sites quantity of Sn-Beta$\mathrm{NH}_{2(30)}$ catalyst was only a little less than the one of Sn-Beta catalyst, which would not influence the process to yield LA obviously. The $\mathrm{CO}_{2}$-TPD profiles of the Beta zeolites and APTMSfunctionalized catalysts were presented in Fig. 4B. It can be seen that the APTMS-functionalized catalysts exhibited the new strong desorption peak located at about $400{ }^{\circ} \mathrm{C}$ associated with moderate base sites at $300-600{ }^{\circ} \mathrm{C},{ }^{22}$ while the zeolites unmodified with amino groups possessed no basic sites obviously. These phenomena confirmed the incorporation of basic groups $\left(-\mathrm{NH}_{2}\right)$.

\section{Catalytic conversion of glucose to lactic acid}

According to above discussion, we discovered that Sn-Beta zeolite, equipped with Lewis acid sites, could be an acid-base bifunctional catalyst by simply modifying with APTMS. Fig. 5 showed the glucose conversion and product yields using different Beta zeolite catalysts. When unmodified commercial Beta zeolite was used as the catalyst, the yields of main products consisting of LA, FA, LeA and HMF were all negligible while the glucose conversion was about $80 \%$. The poor catalytic activity of the commercial Beta zeolite should be attributed to its plentiful Brønsted acid sites and trifling Lewis acid sites internally. While in the presence of deAl-Beta zeolite, the yields of the main products were still low (LA yield $4.78 \%$ ) and the conversion of glucose decreased to $40 \%$ simultaneously. By modifying the deAl-Beta zeolite with APTMS to obtain deAl-Beta- $\mathrm{NH}_{2(30)}$ 


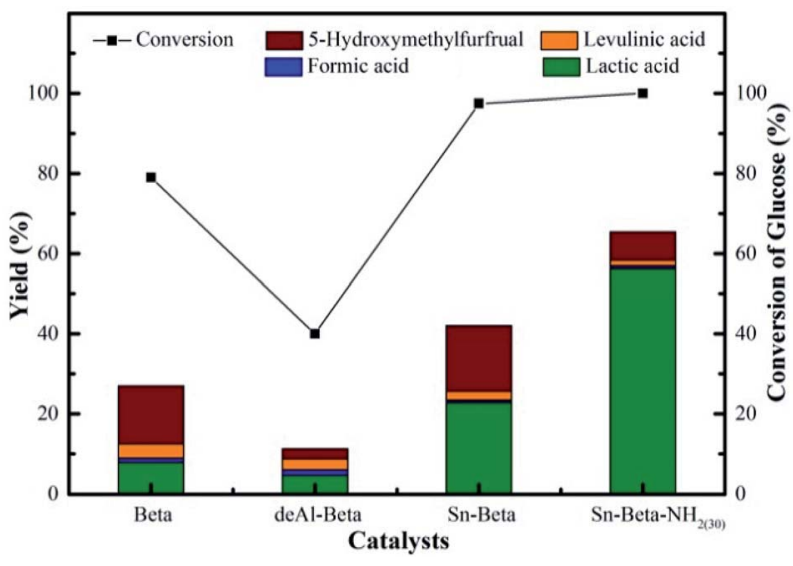

Fig. 5 Conversion of glucose and yield of LA, FA, LeA and HMF over Beta, deAl-Beta, Sn-Beta and APTMS-functionalized catalysts. Reaction conditions: $225 \mathrm{mg}$ of glucose, $160 \mathrm{mg}$ of catalyst, $10 \mathrm{~mL}$ of $\mathrm{H}_{2} \mathrm{O}$, $190{ }^{\circ} \mathrm{C}, 2 \mathrm{~h}$.

zeolite, the LA yield slightly changed to $6.54 \%$. The extremely low $\mathrm{LA}$ yields obtained by deAl-Beta- $\mathrm{NH}_{2(30)}$ indicated that the amino group exhibited no catalytic efficiency towards the main reaction to produce LA. Using Sn-Beta zeolite, however, the conversion of glucose reached up to $90 \%$ and the yield of LA increased to $23 \%$, along with larger amounts of HMF $(16 \%)$, which is similar to the results reported in literatures. ${ }^{14,25,29}$ The catalytic activity of the Sn-Beta zeolite should be ascribed to the incorporation of Sn species into the deAl-Beta zeolite, and the resulted generation of various Lewis acid sites. For comparison, when the Sn-Beta zeolite was modified with $30 \mu \mathrm{L}$ of APTMS to form $\mathrm{Sn}-\mathrm{Beta}-\mathrm{NH}_{2(30)}$, the reaction proceeded with a surprising LA yield (56\%) and a decreasing HMF (7\%) yield. The LA yield using Sn-Beta- $\mathrm{NH}_{2(30)}$ was also slightly higher than that using the bimetallic Zn-Sn-Beta catalyst in our previous work (48\%). ${ }^{14}$ The HMF yield decreased obviously compared to which was obtained by Sn-Beta zeolite. These results suggested that the LA yield was improved significantly upon small addition of APTMS, accompanied by a complete conversion of glucose. Furthermore, the introduction of organoaminos drastically restricted the formation of the main side product HMF.

It is generally known that the glucose-to-LA proceeds through multiple steps of isomerization of glucose to fructose and then conversion of fructose to LA, together with side reaction of the formation of HMF and other subsequent side products. $^{14,28}$ The main reaction to produce LA, is significantly enhanced by the generation of Lewis acid sites. In the meantime, the side reaction to form HMF, could be restrained by the basic $-\mathrm{NH}_{2}$ group (Fig. 6).

\section{Reaction parameter studies}

The performances of Sn-Beta- $\mathrm{NH}_{2}$ catalysts with various dosages of APTMS were studied, as shown in Fig. 7. Without APTMS, only 23\% yield of LA was obtained and the yield of HMF was about $16 \%$. The presence of APTMS with a volume of $30 \mu \mathrm{L}$ remarkably promoted the LA yield to $56 \%$ with glucose conversion up to $100 \%$. Meanwhile, the HMF yield decreased to $7 \%$ and this result indicated that the post-grafted

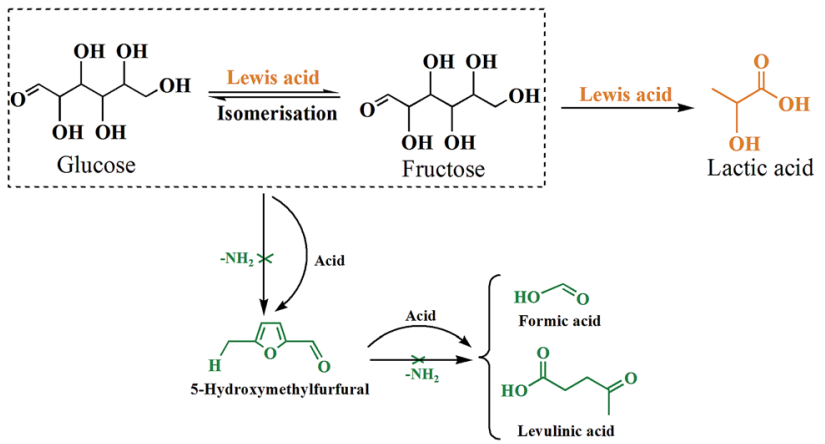

Fig. 6 Proposed reaction pathways in the conversion of glucose to lactic acid.

organoamines indeed inhibit the formation of side products. With a further increase in the APTMS dosage, the glucose conversion remained $100 \%$ but LA yield slightly decreased. When the volume of APTMS used was $200 \mu \mathrm{L}$, the yield of LA decreased to $30 \%$, and the HMF yield was still in decline, down to $4 \%$ approximately. As the APTMS dosage increased, the amount of Lewis acid sites decreased. The present Lewis acid sites could still lead to a glucose conversion of $100 \%$. Meanwhile, the production of LA is closely related to the amount of Lewis acid sites. The sharp decrease of LA yield could be attributed to the excessive alkalinity and the screening of Lewis acid sites caused by amino group on the surface, which also led to the decline in HMF yield. Based on these results, the Sn-Beta$\mathrm{NH}_{2(30)}$ catalyst was selected for subsequent studies since this system resulted in the highest LA yield from glucose.

Fig. 8 and $\mathrm{S} 2 \uparrow$ revealed that the reaction time and reaction temperature had a great effect on both the conversion of glucose and LA yield. At a relatively low reaction temperature (below 190 ${ }^{\circ} \mathrm{C}$ ), the yield of LA first increased and then became almost constant with the increase of reaction time. When the reaction temperature was $150{ }^{\circ} \mathrm{C}$, the LA yield increased from 10 to $32 \%$, in parallel with the increase in the conversion of glucose (91$98 \%$ ) as the reaction time prolonged (Fig. S2 $\dagger$ ). The poor yields should be attributed to the unfavorable temperature condition.

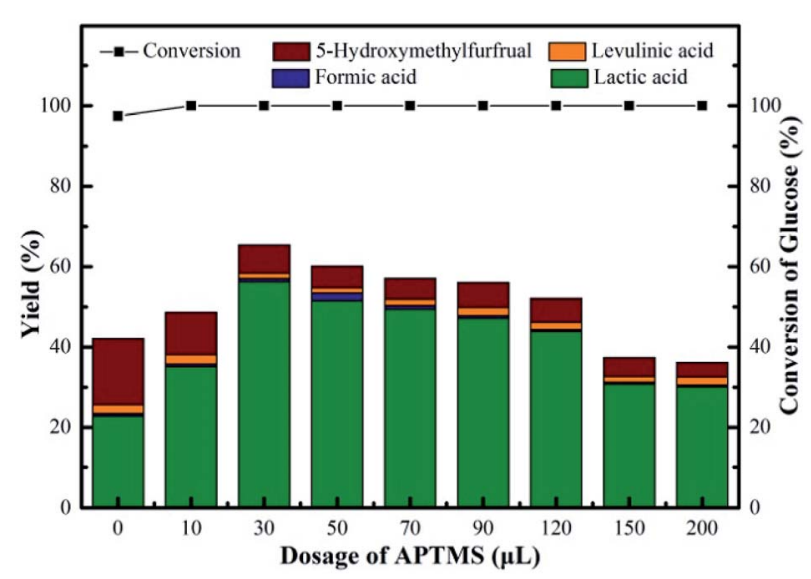

Fig. 7 Conversion of glucose and yield of LA, FA, LeA and HMF over various $\mathrm{NH}_{2}$-supporting catalysts. Reaction conditions: $225 \mathrm{mg}$ of glucose, $160 \mathrm{mg}$ of catalyst, $10 \mathrm{~mL}$ of $\mathrm{H}_{2} \mathrm{O}, 190{ }^{\circ} \mathrm{C}, 2 \mathrm{~h}$. 


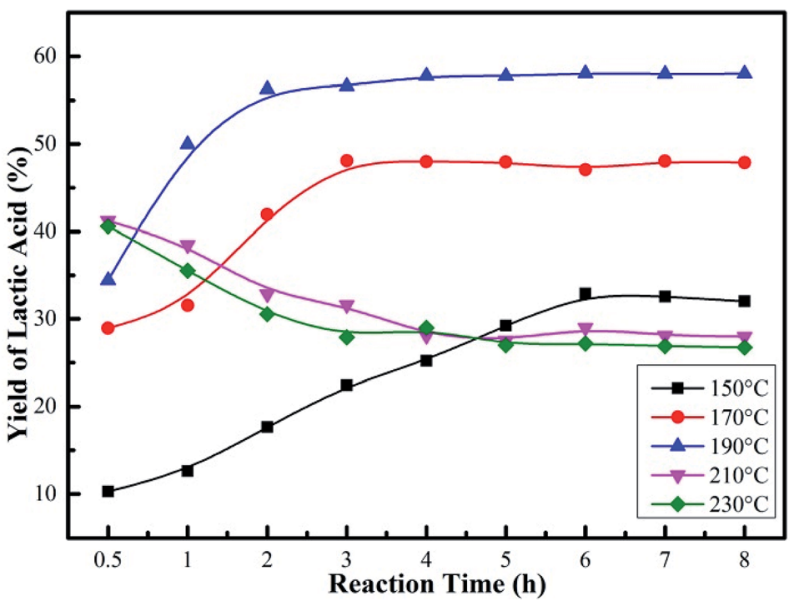

Fig. 8 Effect of reaction temperature and reaction time on yield of $L A$ over Sn-Beta- $\mathrm{NH}_{2(30)}$ catalyst. Reaction conditions: $225 \mathrm{mg}$ of glucose, $160 \mathrm{mg}$ of catalyst, $10 \mathrm{~mL}$ of $\mathrm{H}_{2} \mathrm{O}$.

When the reaction temperature increased to $190{ }^{\circ} \mathrm{C}$, a remarkable LA yield of $56 \%$ was achieved for a $2 \mathrm{~h}$ reaction. As the reaction proceeded, no significant differences in the yield of LA were observed for a longer reaction time. However, a sharp decrease in LA yield was observed when the reaction temperature was over $190{ }^{\circ} \mathrm{C}$, which might be caused by the inactivation of the supporting amino groups. It was suggested that $190{ }^{\circ} \mathrm{C}$ and $2 \mathrm{~h}$ were sufficient for the catalytic reaction, and LA was stable in the system. Moreover, it could be seen that an increase in the reaction temperature not only increased glucose conversion and maximum LA yield, but also shortened the reaction time needed to reach the maximum yield of LA.

Fig. 9 showed the changes in the glucose conversion and LA yield with catalyst dosage over the $\mathrm{Sn}-\mathrm{Beta}-\mathrm{NH}_{2(30)}$ system. The conversion of glucose increased from 98 to $100 \%$ when the dosage of catalyst increased from 40 to $160 \mathrm{mg}$ for a $2 \mathrm{~h}$ reaction, indicating that the influence of increasing catalyst amount to glucose conversion was negligible. Nevertheless, a sharp increase in LA yield (29-56\%) was observed. When the catalyst dosage was $40 \mathrm{mg}$, the conversion of glucose was $98 \%$, while the

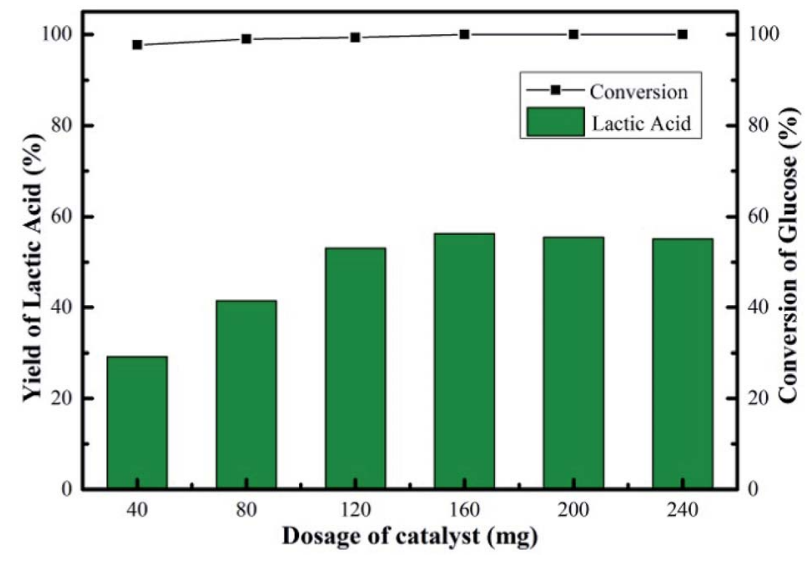

Fig. 9 Effect of catalyst dosage on yield of LA over Sn-Beta- $\mathrm{NH}_{2(30)}$ catalyst. Reaction conditions: $225 \mathrm{mg}$ of glucose, $10 \mathrm{~mL}$ of $\mathrm{H}_{2} \mathrm{O}$, $190^{\circ} \mathrm{C}, 2 \mathrm{~h}$.
LA yield was $29 \%$. In this case, the amount of catalytic sites was relatively insufficient, so it might took a very long period of reaction time to reach a high LA yield. Obviously, compared to other catalyst dosages, a reaction time of $2 \mathrm{~h}$ was not enough for the catalyst dosage of $40 \mathrm{mg}$. In the reaction process, the glucose was nearly completely converted, and some intermediates were formed, mainly including pyruvaldehyde and dihydroxyacetone according to our previous work. ${ }^{\mathbf{1 4}}$ Further increase in catalyst amount (>160 mg), an inconspicuous change in LA yield was observed. The maximum LA yield of 56\% was obtained in the presence of $160 \mathrm{mg}$ of catalyst. The promoted LA yield was attributed to the increase in the accessibility of active sites. Overall, the conversion of glucose increased from 98 to $100 \%$, the yield of LA increased from 29 to $56 \%$ and the change in yields of other products was insignificant with increasing catalyst dosage. Additionally, as part of catalyst efficiency, the effect of initial glucose concentration on LA yield was also investigated. As the glucose dosage increased from 45 to $675 \mathrm{mg}$, glucose conversion decreased slightly from 100 to $96 \%$, and LA yield decreased from 67 to $23 \%$ in the presence of $160 \mathrm{mg}$ of $\mathrm{Sn}-\mathrm{Beta}-\mathrm{NH}_{2(30)}$ catalyst (Fig. S3†). The possible reason accounting for the decrease in LA yield was the reduced availability of active sites to convert glucose to LA. For practical application, apart from LA yield, the products distribution, the reaction parameters optimization and the cost of catalyst recycling are also of vital importance, thus more systematical investigation is still needed.

Following the study of the effect of reaction parameters, the regeneration and reuse of $\mathrm{Sn}-\mathrm{Beta}-\mathrm{NH}_{2(30)}$ catalyst were also examined (Fig. $\mathrm{S} 4 \dagger$ ). After each run, the catalysts were separated by centrifugation and regenerated by washing with ethanol several times. Although the recycled catalysts exhibited similar crystalline structure according to their XRD patterns (Fig. S5 $\dagger$ ), the yield of LA decreased notably to $22 \%$ after recycling for 3 runs. In order to gain further insight into the reason for the decreasing LA yield, Sn content in the reaction solution after reaction and centrifugation. The result of ICP test showed that the Sn content was about $2 \mathrm{mg} \mathrm{L}^{-1}$, indicating that the leaking percent of Sn was below $0.3 \%$, so the decrease of LA yield was not caused by Sn leaking. The decrease might be attributed to the screening of active sites and the prevention of glucose diffusion caused by the coke and humins attached on the surface of catalysts and the leaching of amine groups, which was in accordance with the $\mathrm{C}$ and $\mathrm{N}$ contents shown in Table S1.† Notably, the surface coke and humins of the catalysts cannot be efficiently removed even by the hydrothermal method as mentioned in the catalytic reaction above. Moreover, after the catalyst was calcined at the range of $300-550{ }^{\circ} \mathrm{C}$ for $3-6 \mathrm{~h}$, the yield of LA was still 20-25\%. Therefore, more systematic studies on this issue are required.

\section{Conclusions}

In conclusion, we synthesized a series of Sn-Beta- $\mathrm{NH}_{2}$ catalysts by means of SSIE and post-grafting organoamines. The catalysts contained both Lewis acid sites and moderate base sites according to the Py-IR and $\mathrm{CO}_{2}$-TPD characterization. The acid- 
base bifunctional catalyst could efficiently convert glucose to LA and the side reaction was well suppressed. Using Sn-Beta$\mathrm{NH}_{2(30)}$ catalyst, $56 \%$ LA yield was obtained under optimized hydrothermal conditions $\left(190{ }^{\circ} \mathrm{C}, 2 \mathrm{~h}\right)$ along with only $7 \% \mathrm{HMF}$ yield. It was evidenced that by the introduction of base sites into the Lewis acid catalyst, such a high yield of LA could be achieved. We hope that this work would be helpful for synthesizing highly efficient heterogeneous catalysts for biomass conversion.

\section{Conflicts of interest}

The authors declare no competing interests.

\section{Acknowledgements}

This work is supported by the National Natural Science Foundation of China (21676205), the National Science Fund for Distinguished Young Scholars (51625804), the National Key R\&D Program of China (2018YFD1100503) and the Fundamental Research Funds for the Central Universities (22120190012, 22120190054).

\section{Notes and references}

1 A. Corma, S. Iborra and A. Velty, Chem. Rev., 2007, 107, 24112502.

2 M. Dusselier, P. Van Wouwe, A. Dewaele, E. Makshina and B. F. Sels, Energy Environ. Sci., 2013, 6, 1415-1442.

3 G. W. Huber, S. Iborra and A. Corma, Chem. Rev., 2006, 106, 4044-4098.

4 A. J. Straathof, Chem. Rev., 2014, 114, 1871-1908.

5 S. Dutta, J. Kim, Y. Ide, J. H. Kim, M. S. A. Hossain, Y. Bando, Y. Yamauchi and K. C. W. Wu, Mater. Horiz., 2017, 4, 522545.

6 S. Dutta, A. Bhaumik and K. C. W. Wu, Energy Environ. Sci., 2014, 7, 3574-3592.

7 J. Kuo, N. Suzuki, Y. Yamauchi and K. C. W. Wu, RSC Adv., 2013, 3, 2028-2034.

8 Y. Y. Li and K. C. W. Wu, Phys. Chem. Chem. Phys., 2012, 14, 13914-13917.

9 W. H. Hsu, Y. Y. Lee, W. H. Peng and K. C. W. Wu, Catal. Today, 2011, 174, 65-69.

10 R. Datta and M. Henry, J. Chem. Technol. Biotechnol., 2006, 81, 1119-1129.

11 P. Maki-Arvela, I. L. Simakova, T. Salmi and D. Y. Murzin, Chem. Rev., 2014, 114, 1909-1971.

12 W. P. Deng, Y. Z. Wang, S. Zhang, K. M. Gupta, M. J. Hülsey, H. Asakura, L. M. Liu, Y. Han, E. M. Karp, G. T. Beckham, P. J. Dyson, J. W. Jiang, T. Tanakac, Y. Wang and N. Yan, Proc. Natl. Acad. Sci. U. S. A., 2018, 115, 5093-5098.

13 X. Y. Lv, B. Yu, X. W. Tian, Y. Chen, Z. J. Wang, Y. P. Zhuang and Y. H. Wang, J. Taiwan Inst. Chem. Eng., 2016, 61, 124131.

14 W. J. Dong, Z. Shen, B. Y. Peng, M. Y. Gu, X. F. Zhou, B. Xiang and Y. L. Zhang, Sci. Rep., 2016, 6, 26713.

15 W. P. Deng, Y. Wang and N. Yan, Curr. Opin. Green Sustain. Chem., 2016, 2, 54-58.
16 T. L. Wang, W. P. Deng, B. J. Wang, Q. H. Zhang, X. Y. Wan, Z. C. Tang, Y. Wang, C. Zhu, Z. X. Cao, G. C. Wang and H. L. Wan, Nat. Commun., 2013, 4, 2141.

17 X. Lei, F. F. Wang, C. L. Liu, R. Z. Yang and W. S. Dong, Appl. Catal., A, 2014, 482, 78-83.

18 S. Lux and M. Siebenhofer, Catal. Sci. Technol., 2013, 3, 1380-1385.

19 F. F. Wang, C. L. Liu and W. S. Dong, Green Chem., 2013, 15, 2091-2095.

20 D. Cao, W. J. Cai, W. T. Tao, S. Y. Zhang, D. Z. Wang and D. Z. Huang, Catal. Lett., 2017, 147, 926-933.

21 Y. Q. Wang, F. M. Jin, M. W. Sasaki, F. W. Wang, Z. Z. Jing and M. Goto, AIChE J., 2013, 59, 2096-2104.

22 W. Zeng, D. G. Cheng, F. Q. Chen and X. L. Zhan, Catal. Lett., 2009, 133, 221-226.

23 F. Chambon, F. Rataboul, C. Pinel, A. Cabiac, E. Guillon and N. Essayem, Appl. Catal., B, 2011, 105, 171-181.

24 F. F. Wang, J. Liu, H. Li, C. L. Liu, R. Z. Yang and W. S. Dong, Green Chem., 2015, 17, 2455-2463.

25 M. S. Holm, S. Saravanamurugan and E. Taarning, Science, 2010, 328, 602-605.

26 J. Dijkmans, D. Gabriëls, M. Dusselier, F. Clippel, P. Vanelderen, K. Houthoofd, A. Malfliet, Y. Pontikes and B. F. Sels, Green Chem., 2013, 15, 2777-2785.

27 M. Moliner, Y. Roman-Leshkov and M. E. Davis, Proc. Natl. Acad. Sci. U.S.A., 2010, 107, 6164-6168.

28 J. Zhang, L. Wang, G. X. Wang, F. Chen, J. Zhu, C. T. Wang, C. Q. Bian, S. X. Pan and F. S. Xiao, ACS Sustainable Chem. Eng., 2017, 5, 3123-3131.

29 Y. Wan, M. Q. Zhuang, S. P. Chen, W. D. Hu, J. Sun, J. D. Lin, S. L. Wan and Y. Wang, ACS Catal., 2017, 7, 6038-6047.

30 X. C. Wang, Y. L. Song, C. P. Huang, F. B. Liang and B. H. Chen, Green Chem., 2014, 16, 4234-4240.

31 L. D. White and C. P. Tripp, J. Colloid Interface Sci., 2000, 232, 400-407.

32 J. Yang, B. Tang, W. L. Dai, L. D. Li, G. J. Wu and N. J. Guan, Sci. Sin.: Chim., 2015, 45, 396-404.

33 S. G. Wang, Catal. Commun., 2003, 4, 469-470.

34 J. C. Hicks, R. Dabestani, A. C. Buchanan and C. W. Jones, Chem. Mater., 2006, 18, 5022-5032.

35 M. W. McKittrick and C. W. Jones, J. Am. Chem. Soc., 2004, 126, 3052-3053.

36 K. K. Sharma and T. Asefa, Angew. Chem., Int. Ed., 2007, 119, 2937-2940.

37 B. Xu, Y. Q. Liu, J. G. Wang, X. Q. Ren, W. M. Ma and W. L. Wu, J. Chem. Eng. Chin. Univ., 2015, 29, 335-340.

38 C. Hammond, S. Conrad and I. Hermans, Angew. Chem., Int. Ed., 2012, 51, 11736-11739.

39 P. Wolf, M. Valla, A. J. Rossini, A. Comas-Vives, F. NunezZarur, B. Malaman, A. Lesage, L. Emsley, C. Coperet and I. Hermans, Angew. Chem., Int. Ed., 2014, 53, 10179-10183.

40 H. Y. Luo, L. Bui, W. R. Gunther, E. Min and Y. RománLeshkov, ACS Catal., 2012, 2, 2695-2699.

41 M. Chong and X. S. Zhao, J. Phys. Chem. B, 2003, 103, 1265012657. 